\title{
MORPHOLOGICAL AND DEVELOPMENTAL STUDIES ON THE EGGS OF FOUR CORYPHOPTERUS SPECIES (ACTINOPTERYGII: GOBIIDAE) IN THE CARIBBEAN SEA
}

\author{
Annemarie KRAMER and Robert A. PATZNER
}

Department of Organismic Biology, University of Salzburg, Austria

\begin{abstract}
Kramer A., Patzner R.A. 2008. Morphological and developmental studies on the eggs of four Coryphopterus species (Actinopterygii: Gobiidae) in the Caribbean Sea. Acta Ichthyol. Piscat. 38 (2): 97-102.
\end{abstract}

Background. Morphology of eggs and embryonic development of the genus Coryphopterus are documented for the first time. The species $C$. venezuelae, $C$. dicrus, C. eidolon, and C. thrix have been found to have a similar ecology, but details about their reproduction are still unclear. The aim of the present study was to investigate if egg morphology, mode of attachment, and development differ between the species; which could be attributed to use of different microhabitats and/or resources.

Materials and methods. Fish were kept in aquaria and their eggs were collected every 6 h. Embryonic development in the eggs was documented under a dissecting microscope. Additionally egg morphology and mode of egg attachment were studied by a scanning electron microscope.

Results. The time of embryonic development was $66 \mathrm{~h}$ in all species. Egg dimensions were $0.7-1.1 \mathrm{~mm}$ in length and $0.3-0.5 \mathrm{~mm}$ in width. The eggs were attached to the substrate by an adhesive apparatus typical for gobiids, a net like structure around the micropylar pole, and composed of filaments, $1.5-2.2 \mu \mathrm{m}$ in diameter. The zona radiata was of $0.5-0.8-\mu \mathrm{m}$ thick.

Conclusion. No differences in the period of embryonic development, egg shape or means of attachment could be found between the species studied, but variations in egg dimensions and their attaching structures were noted. The zona radiata is very thin in comparison to other fish eggs, though comparative data of fish with a similar ecology are needed.

Keywords: Coryphopterus, embryonic development, scanning electron microscope, egg morphology, zona radiata

\section{INTRODUCTION}

Currently, the gobiid genus Coryphopterus Gill, 1863 includes 13 western Atlantic species (Victor 2008). The sand dwelling species have been reported to live in similar habitats and therefore the question arises in how far they differ in ecological aspects such as their reproductive biology. No information has been presented on that topic, in particular their egg morphology, mode of attachment and development of eggs. This study investigates the morphology of eggs as well as aspects of their development and compares the results within the genus and to other gobiids. Eggs of Coryphopterus venezuelae Cervigón, 1966; Coryphopterus dicrus Böhlke et Robins, 1960; Coryphopterus eidolon Böhlke et Robins, 1960; and Coryphopterus thrix Böhlke et Robins, 1960 were collected under laboratory conditions and studied under a scanning electron microscope (SEM). These species are of similar size, with a maximum length of 5-7 $\mathrm{cm}$ and live associated with coral reefs. Eggs are deposited under stones or rocks and guarded by the male till hatching (Thresher 1984).
The eggshell is called zona radiata or chorion and has been reported to vary in thickness, surface structure, and adhesive filaments. In many cases the zona radiata can be used to identify species (Riehl 1995, Riehl and Patzner 1998, Giulianini and Ferrero 2000). Its main function is to protect the embryo from mechanical forces. Normally it measures between 5 and $15 \mu \mathrm{m}$ in thickness, but may reach up to $100 \mu \mathrm{m}$ in species like Agonus cataphractus (L.) (Actinopterygii: Agonidae), which deposit their eggs in tidal wave zones (Riehl 1995). Typically gobiid fishes lay their eggs in a dense patch of single layers on the underside of a solid structure e.g., stones, rocks or shells and the male guards them until they hatch (Miller 1984, Thresher 1984). A characteristic feature of gobiid eggs is the formation of a layer of filaments between the follicle granulosa and the zona radiata. These filaments are arranged around the micropylar pole to provide a mode of attachment for these demersal eggs (Miller 1984). Giulianini et al. (2001) have proved that spermatozoa can pass through

\footnotetext{
* Correspondence: Dr. Annemarie Kramer, Universität Salzburg, Fachbereich für Organismische Biologie, Hellbrunnerstr. 34, 5020 Salzburg, Austria, phone: +436802177721, fax: +4366280445698 e-mail: annemariekramer@gmx.net
} 
these nets of filaments to reach the micropyle and fertilize the egg, even after being attached to the substrate.

\section{MATERIAL AND METHODS}

Eggs were obtained from fish under laboratory conditions. Female fish were in the range (standard length) of $2.8-5.2 \mathrm{~cm}$ (mean $3.8 \pm 0.7$ ) for $C$. venezuelae $(n=9)$, $3.2-4.5 \mathrm{~cm}$ (mean $3.8 \pm 0.4$ ) for C. eidolon $(n=13)$, $2.4-4.2 \mathrm{~cm}$ (mean $3.1 \pm 0.6)$ for $C$. dicrus $(n=7)$ and

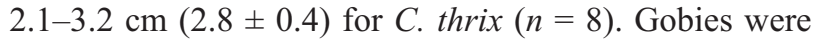
kept in aquaria which were permanently supplied with fresh seawater at a temperature between $28^{\circ} \mathrm{C}$ and $32^{\circ} \mathrm{C}$ (mean $30 \pm 1$ ) with the natural cycle of daylight. The bottom of the aquarium was supplied with sand and segments of polyvinyl chloride (PVC) pipes of different diameters and lengths. Each PVC pipe was lined with an acetate sheet to enable the collection of deposited eggs (Privitera 2001). All eggs were sampled with the acetate sheet and preserved in $1 \%-2 \%$ formaldehyde for 2 days, then stored in $70 \%$ ethanol. After fertilization samples of the developing eggs were taken every $6 \mathrm{~h}$, photographed under a dissecting microscope and the state of development was described (Colin 1975, Kanabashira et al. 1980, Faria et al. 2002). Egg dimensions were measured under the dissecting microscope after preservation. Length was defined as the longest distance between the animal and vegetal pole and width as widest part of the egg; 20 eggs of each species were measured.

For the SEM study, eggs were fixed in osmium tetroxide, dehydrated in alcohol $(80 \%, 90 \%, 96 \%$, and $100 \%)$ and critical-point-dried (Baltec CPD030 critical point dryer), fixed on aluminium stubs, coated with gold (Agar sputter coater), and studied under a scanning electron microscope (SEM, Philips XL-30), where they were photographed and measured. Surface structure and thickness of the zona radiata of eggs, which have previously been cut into halves as well as mode of attachment to the substrate were documented. Measurements of the zona radiata were taken on several locations $(n)$ for $C$. venezuelae on two eggs $(n=10)$, for $C$. eidolon on four eggs $(n=14)$ and for $C$. dicrus on six eggs $(n=17)$. The diameter of the eggs adhesive filaments was measured on 11 eggs $(n=89)$, 9 eggs $(n=91), 1$ egg $(n=8)$, and 8 eggs $(n=78)$ from C. venezuelae, C. eidolon, C. dicrus, and C. thrix, respec- tively. Statistical analyses were performed using SigmaStat $^{\circledR} 2.03$ (SPSS Inc., Chicago).

\section{RESULTS}

Egg measurements are summarized in Table 1. A Student's $t$-test was used to compare mean values of different measurements and the results are presented as mean \pm standard deviation in the table. The thickness of the zona radiata showed a statistically significant difference between $C$. venezuelae and $C$. eidolon $(P=0.011)$. Diameters in egg filaments had a highly significant difference $(P<0.001)$ between $C$. venezuelae and $C$. thrix, C. eidolon and C. thrix, as well as $C$. thrix and C. dicrus; a significant difference $(P=0.044)$ between $C$. venezuelae and $C$. eidolon. Highly significant differences $(P<0.001)$ were found in length and width of egg between all species but length in $C$. venezuelae and C. thrix $(P=0.002)$, which still show significant difference, and width in $C$. venezuelae and $C$. thrix $(P=0.849)$.

The eggs were ellipsoidal or oval in shape (Fig. 1A). The mode of attachment of the adhesive filaments to the substrate was studied and compared between the Coryphopterus species (Figs. 1A-C). In all four species a very similar pattern in egg attachment was observed. The attaching structure formed a circular, net-like pattern around the micropylar pole, which divides distally into single filaments approximately $2 \mathrm{~mm}$ in diameter (Figs. 1A-C, Table 1). The net-like structure, which attaches the eggs to the substrate, was small in C. thrix and C. dicrus (Fig. 1B), but large and well developed in $C$. venezuelae and C. eidolon (Figs. 1A, 1C). Under the SEM eggs of all four species had smooth surfaces and did not show any structures or specific patterns other than the adhesive filaments (Figs. 1A-D). At the animal pole the closed micropyle was visible; for $C$. venezuelae it measured $15 \mu \mathrm{m}$ in diameter. Around the micropyle the attaching filaments originate from a circular area (Fig. 1E).

The embryonic development for all four Coryphopterus species is documented below.

- 0 h Balloon-shaped eggs were attached to the substrate with adherent filaments (Fig. 2A).

- $12 \mathrm{~h}$ The embryo becomes visible (Fig. 2B).

- $24 \mathbf{h}$ The head could be distinguished from the body. Faint pigmentation is visible along the ventral surface

Thickness of the zona radiata and diameter of the adhesive filaments of Coryphopterus eggs as measured under the scanning electron microscope as well as egg dimensions and total length of larvae of Coryphopterus measurements taken under a dissecting microscope (mean \pm standard deviation; values are rounded)

\begin{tabular}{lccccc}
\hline & $\begin{array}{c}\text { Zona radiata } \\
{[\mu \mathrm{m}]}\end{array}$ & $\begin{array}{c}\text { Filaments } \\
{[\mu \mathrm{m}]}\end{array}$ & $\begin{array}{c}\text { Egg length } \\
{[\mathrm{mm}]}\end{array}$ & $\begin{array}{c}\text { Egg width } \\
{[\mathrm{mm}]}\end{array}$ & $\begin{array}{c}\text { Total length of larvae } \\
{[\mathrm{mm}]}\end{array}$ \\
\hline C. venezuelae & $0.6 \pm 0.1$ & $2.2 \pm 0.5$ & $1.1 \pm 0.0$ & $0.4 \pm 0.0$ & $1.8 \pm 0.1$ \\
C.eidolon & $0.5 \pm 0.0$ & $2.0 \pm 0.5$ & $1.1 \pm 1$ & $0.4 \pm 0.0$ & $1.7 \pm 0.1$ \\
C.dicrus & $7 \pm 0.1$ & $2.1 \pm 0.3$ & $0.6 \pm 0.1$ & $0.4 \pm 0.0$ & - \\
C.thrix & - & $1.5 \pm 0.4$ & $1.1 \pm 0.1$ & $0.4 \pm 0.0$ & $1.7 \pm 0.1$ \\
\hline
\end{tabular}


and on the yolk sac; the eye pigmentation and body segmentation appear; and the embryo exhibits movement. The yolk sac occupies approximately $25 \%-33 \%$ of the eggs volume.

- $36 \mathbf{h}$ The yolk sac decreases in size, it has approximately the same size as the embryos head. Pigments become darker and are more numerous on the ventral side of the body (Fig. 2C).

- $42 \mathrm{~h}$ The eyes are not yet completely developed.

- $48 \mathrm{~h}$ The body segmentation of the embryo is clearly visible, as well as the pigmentation on the ventral side; eyes are not completely pigmented; and the yolk sac has shrunk to approximately the size of the head of the embryo (Fig. 2D).

- $60 \mathrm{~h}$ The eyes of the embryo are completely developed. Dark pigmentation is visible along the ventral side of the body. The yolk sac is smaller than the head of the embryo. Small, transparent pectoral fins become visible (Fig. 2E).

- $66 \mathrm{~h}$ Larvae hatch. On their ventral side, pigmentation is visible all over the body, without showing a specific pattern. The body is transparent and the muscles and guts could be seen (Fig. 2F).

In all 4 Coryphopterus species, hatching occurred at night, after $66 \mathrm{~h}$ (46 observations). In some cases, larvae started to hatch earlier, when handled for photographing or sampling. In a few occasions, larvae with a yolk sac were observed. All larvae showed a positive phototactic reaction. After preservation with formaldehyde (2\%) and alcohol larvae were measured under a stereoscope. Their sizes ranged from $1.5 \mathrm{~mm}$ for $C$. dicrus to $2.0 \mathrm{~mm}$ for C. eidolon (Table 1). A $t$-test showed highly significant differences in length between $C$. eidolon and $C$. venezuelae $(P<0.001)$ and significant differences between C. eidolon and $C$. dicrus $(P=0.030)$, as well as C. venezuelae and $C$. dicrus $(P=0.002)$.

\section{DISCUSSION}

Gobies have a wide range of egg size; small eggs are present not only in many freshwater species but also in a number of small marine species with a planktonic phase. However without this planktonic phase present, gobies in slow rivers, lagoons, and brackish waters, which often lack such a phase, have larger eggs (Miller 1984). The sizes of eggs and larvae as well as the shape of the eggs observed in the present study are within the range of 15 other species of subtropical to tropical marine gobies: Egg size has been reported to vary from $0.65-1.93 \mathrm{~mm}$ in length and $0.47-0.60 \mathrm{~mm}$ in width (Miller 1984, Privitera 2001). Newly hatched larvae of subtropical and tropical marine gobies had a body length of 1.56-3.07 $\mathrm{mm}$ in total length, whereas species from temperate waters have larger eggs and larvae (Privitera 2001). Egg size can be species specific and correlated with body size of fish and/or environ- mental conditions (Miller 1984, Tamada and Iwata 2005, Herler et al. 2006).

Statistical analyses on a larger set of data may show different results; when looking at the strength of adhesive filaments and thickness of the zona radiata, it must be kept in mind that they vary depending on the location where the measurement was taken (Giulianini and Ferrero 2000).

The thickness and structure of the zona radiata often reflect adaptations to the ecological environment of the fish; previous studies have come to the conclusion that fish, which do not need protection of their eggs from mechanical forces, have a thinner zona radiata (Riehl and Greven 1993, Riehl 1995). Eggs of Coryphopterus species in the present study had zona radiata between 0.5 and $0.8 \mathrm{~mm}$. Goodeid fish, which are viviparous freshwater species, have been reported to have eggshells between 0.5 and $1.5 \mu \mathrm{m}$ (Riehl and Greven 1992). The studied Coryphopterus eggs are well protected from mechanical forces inside the burrow, where they are fixed to the substrate and fanned by the male to supply them with oxygen. A thin zona radiata favours the exchange of gases and metabolic waste substances of the embryo (Rombough 1988, Riehl 1995). No comparative data are available on the characteristics of marine tropical gobiid eggs, or species with a similar reproduction mode or ecology.

Other SEM studies on gobiid eggs noted similar modes of attachment to the substrate (Herler et al. 2006). The attaching apparatus, which consists of filaments around the micropylar region, is also observed in other teleost families such as Blenniidae, Gobiesocidae, Opistognathidae, Grammatidae, and Plesiopidae (cf. Takahashi 1978, Patzner 1984, Mooi 1990, Breining and Britz 2000).

In the presently described study the eggs hatched after $66 \mathrm{~h}$ or on their third day of development at a water temperature of $28-32^{\circ} \mathrm{C}$. Sponaugle and Cowen (1994) report that eggs of Coryphopterus glaucofraenum Gill, 1863 hatch after 4 days. Additionally in some laboratory studies eggs of Coryphopterus personatus (Jordan et Thompson, 1905) hatch after 5 to 6 days at a water temperature of $27-29^{\circ} \mathrm{C}$, and eggs of another tropical marine gobiid, Asterropteryx semipunctata Rüppell, 1830, hatch after 4 to 5 days at $23-24^{\circ} \mathrm{C}$ (Cole and Robertson 1988, Privitera 2001).

Baldwin and Smith (2003) describe specific melanophore patterns for Coryphopterus spp. In the present study no species-specific patterns were found, pigmentation differed between individual fish, which means that those specific patterns are developed after larvae have hatched.

The present study gives an overview on the embryonic development and egg morphology of four sand dwelling gobiids of the genus Coryphopterus. Ecological explanations and physiological details on the egg morphology remain a subject for future studies. It will be of interest to study details on fish with similar ecology_-gobiids and other bottom spawners - to get comparative data. 

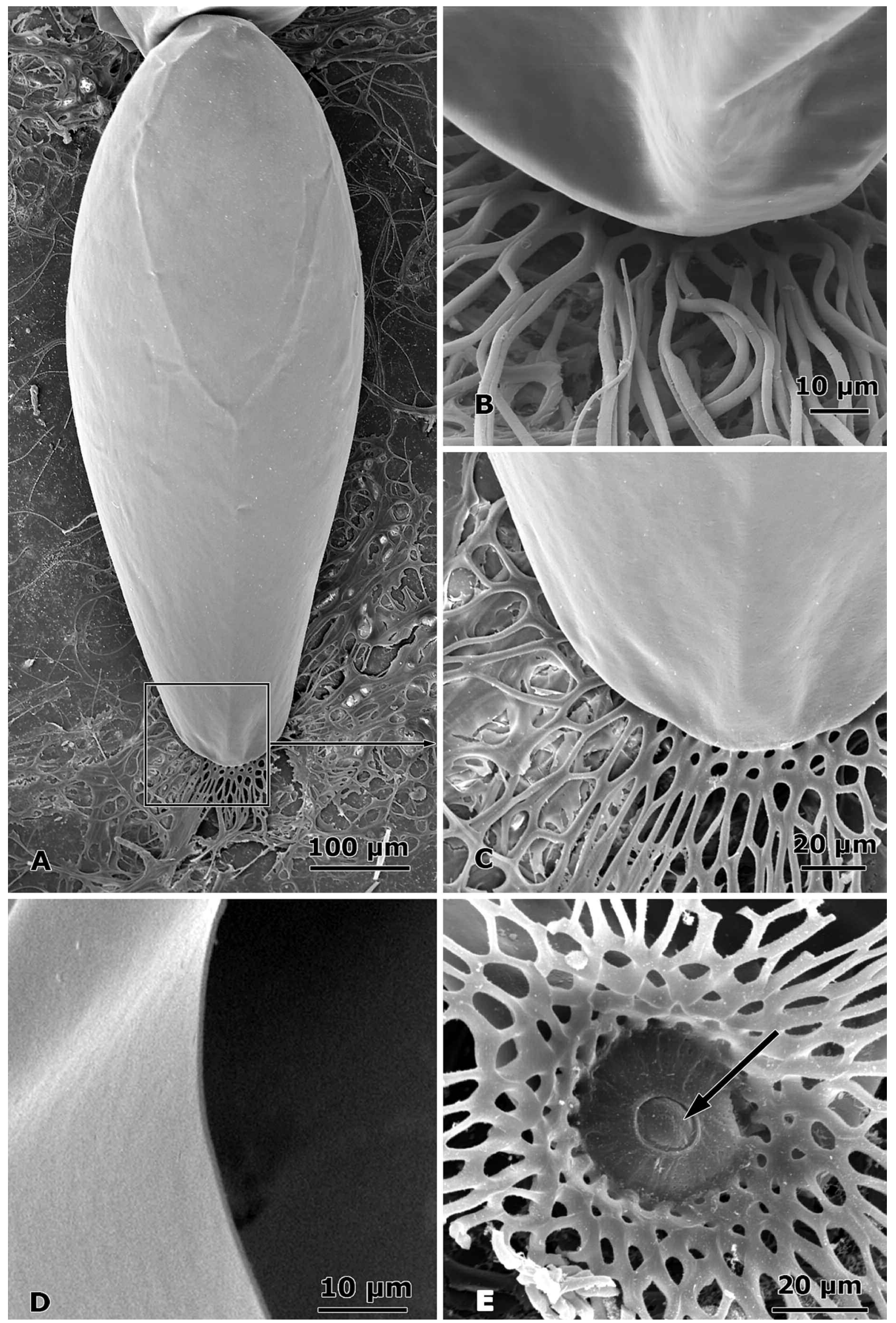

Fig. 1. Eggs of Coryphopterus by scanning electron microscope; A. Egg of C. venezuelae with attaching structure at the bottom; B. Egg of C. dicrus; animal pole with attaching filaments; C. Egg of C. venezuelae (detail of Fig. 1A); animal pole with a net like attaching structure; D. Egg of C. dicrus; zona radiata; left = outside of egg; E. Egg of C. venezuelae; view at closed micropyle and attaching filaments at micropylar pole, on the undersurface of the egg 


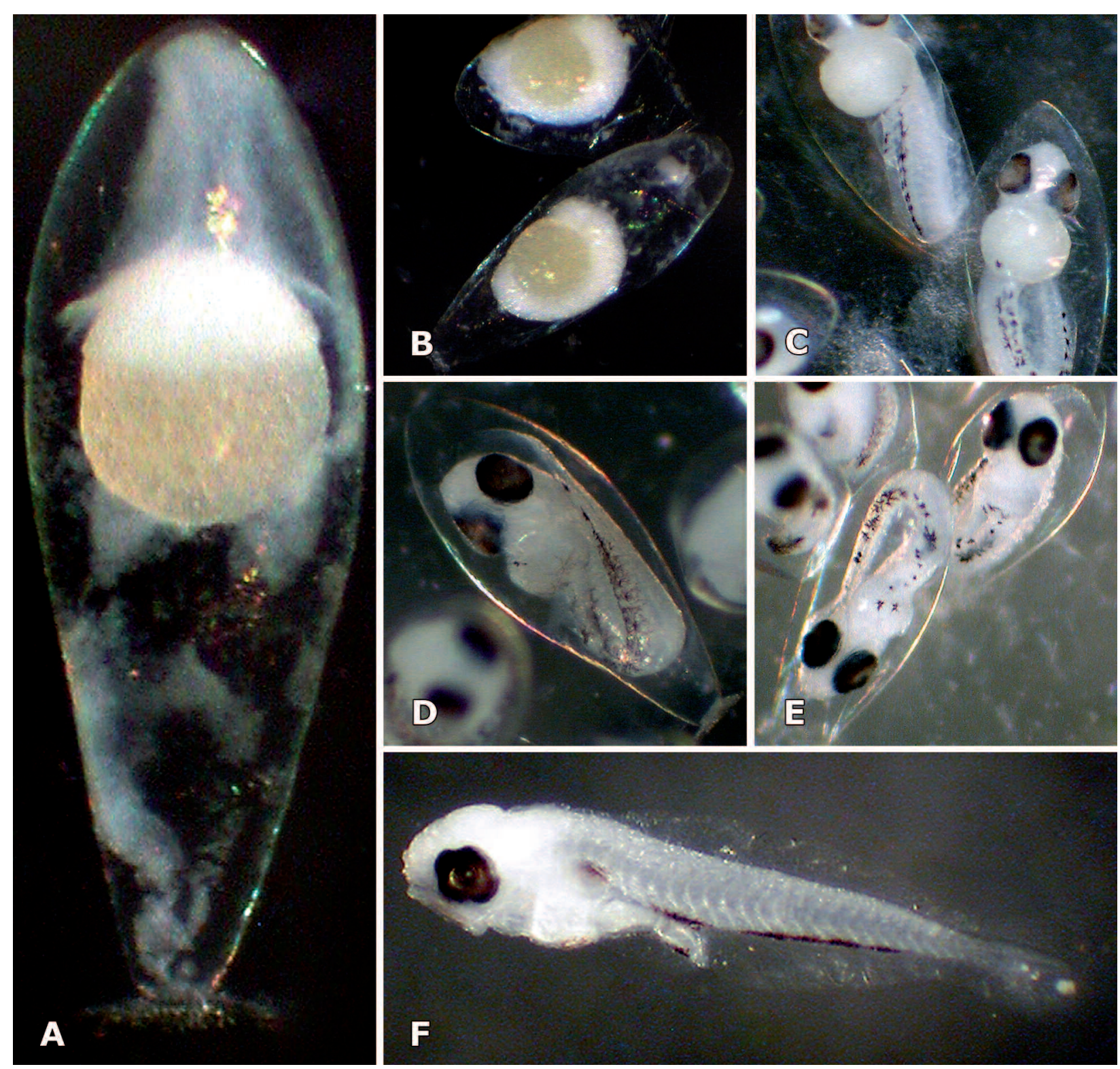

Fig. 2. Egg of Coryphopterus dicrus (A) and C. venezuelae (B-F) at different intervals after deposition; A. Age of 6 h; cell division is clearly visible toward the vegetal pole of the yolk; B. Age of $12 \mathrm{~h}$; the embryo is distinguishable from the yolk; C. Age of $36 \mathrm{~h}$; the eyes are started to be pigmented, ventral side of the embryo is clearly visible; D. Age of $48 \mathrm{~h}$; the yolk sac has shrunk to the size of the embryos head; E. Age of $60 \mathrm{~h}$; the embryos yolk sac is very small, pigmentation and formation of the eyes are almost completed; $\mathbf{F}$. Recently hatched larvae at the age of $66 \mathrm{~h}$; dorsal, tail and ventral fins are transparent

\section{ACKNOWLEDGEMENTS}

We are gratefully thanking the Curaçao Sea Aquarium, especially Mr. Steve Piontek, for providing SCUBA equipment and laboratory facilities, Mr. José G. Bernal Rodríguez for his field assistance, Mr. Nabil Mansour for corrections on the manuscript and Mr. James L.Van Tassell for his help. The fieldwork was partly financed by the University of Salzburg and Land Salzburg.

\section{REFERENCES}

Baldwin C.C., Smith D.G. 2003. Larval Gobiidae (Teleostei: Perciformes) of Carry Bow Cay, Belize, Central America. Bulletin of Marine Science 72: 639-674.
Breining P., Britz T. 2000. Egg structure of three clingfish species, using scanning electron microscopy. Journal of Fish Biology 56: 1129-1137.

Cole K.S., Robertson D.R. 1988. Protogyny in the Caribbean reef goby, Coryphopterus personatus: gonad ontogeny and social influences on sex change. Bulletin of Marine Science 42: 317-333.

Colin P.L. 1975. The neon gobies: The comparative biology of the genus Gobiosoma, subgenus Elacatinus, (Pisces: Gobiidae) in the Tropical Western North Atlantic Ocean. T.F.H. Publications. Neptune, New Jersey.

Faria C., Borges R., Gil F., Almada V.C., Gonçalves E.J. 2002. Embryonic and larval development of Lipophrys pholis (Pisces: Blenniidae). Scientia Marina 66: 21-26. 
Giulianini P.G., Ferrero E.A. 2000. Ultrastructural aspects of the ovarian follicle and egg envelope of the sea-grass goby Zosterisessor ophiocephalus (Osteichthyes, Gobiidae). Italian Journal of Zoology 68: 29-37.

Giulianini P.G., Ota D., Marchesan M., Ferrero E.A. 2001. Can goby spermatozoa pass through the filament adhesion apparatus of laid eggs? Journal of Fish Biology 58: 1750-1752.

Herler J., Patzner R.A., Hilgers H. 2006. Notes on the egg envelope and number of oocytes in two Gobius species (Teleostei: Gobiidae) from the northern Adriatic. Zeitschrift für Fischkunde 8: 1-7.

Kanabashira Y., Sakai H., Yasuda F. 1980. Early development and reproductive behaviour of the gobiid fish, Mugiologobius abei. Japanese Journal of Ichthyology 27: 191-198.

Miller P.J. 1984. The tokology of gobioid fishes. Pp. 119-153. In: Potts G.W., Wotton R.J. (eds.). Fish reproduction. Strategies and tactics. Academic Press, London.

Mooi R.D. 1990. Egg surface morphology of pseudochromoids (Perciformes: Percoidei), with comments on its phylogenetic implications. Copeia 2: 455-475.

Patzner R.A. 1984. The reproduction of Blennius pavo (Teleostei, Blennidae). II. Surface structure of the ripe egg. Zoologischer Anzeiger 213: 44-50.

Privitera L.A. 2001. Characteristics of egg and larval production in captive bluespotted gobies. Journal of Fish Biology 58: 1211-1220. DOI:10.1006/jfbi.2000.1527.

Riehl R. 1995. Die Eier und Eihüllen von Knochenfischen. Pp.11-16. In: Greven H., Riehl R. (eds.) Fortpflanzungsbiologie der Aquarienfische. Birgit Schmettkamp Verlag, Bornheim.

Riehl R., Greven H. 1993. Fine structure of egg envelopes in some viviparous goodeid fishes with comments on the relation of envelope thinness to viviparity. Canadian Journal of Zoology 71: 91-97.
Riehl R., Patzner R.A. 1998: Minireview: The modes of attachment in eggs of teleost fishes. Italian Journal of Zoology $\mathbf{6 5}$ : 415-420.

Rombough P.J. 1988. Respiratory gas exchange, aerobic metabolism, and effects of hypoxia during early life. Pp. 59-161. In: Hoar W.S., Randall A.J. (eds.) Fish physiology. Vol. XI, Part A. Academic Press, New York.

Sponaugle S., Cowen R.K. 1994. Larval durations and recruitment patterns of two Caribbean gobies (Gobiidae): contrasting early life histories in demersal spawners. Marine Biology 120: 133-143.

Takahashi S. 1978. The adherent filaments of the eggs of Isaza (Chaenogobius isaza Tanaka, Pisces). Zoological Magazine 87: 216-220.

Tamada K., Iwata K. 2005. Intra-specific variations of egg size, clutch size and larval survival related to maternal size in amphidromous Rhinogobius goby. Environmental Biology of Fishes 73: 379-389. DOI:10.1007/s10641-005-2230-8.

Thresher R.E. 1984. Reproduction in reef fishes. T.F.H. Publications Inc., Ltd., Neptune City.

Victor B. 2007. Coryphopterus kuna, a new goby (Perciformes: Gobiidae: Gobiinae) from the western Caribbean, with the identification of the late larval stage and an estimate of the pelagic larval duration. Zootaxa 1526: 51-61.

Victor B. 2008. Redescription of Coryphopterus tortugae (Jordan) and a new allied species Coryphopterus bol (Perciformes: Gobiidae: Gobiinae) from the tropical western Atlantic Ocean. Journal of the Ocean Science Foundation 1: 1-19.

Received: 9 April 2008

Accepted: 18 July 2008

Published electronically: 30 November 2008 